OPEN ACCESS

Edited by:

Sunjoo Kang,

Yonsei University, South Korea

Reviewed by:

Kimberley Shoaf,

The University of Utah, United States Miodraga Stefanovska-Petkovska, Universidade de Lisboa, Portugal

*Correspondence: Mohammad Tahir Waheed tahirwaheed@qau.edu.pk

Specialty section: This article was submitted to Public Health Education and Promotion, a section of the journal Frontiers in Public Health

Received: 11 February 2019 Accepted: 18 June 2019 Published: 03 July 2019

Citation:

Malik MS, Afzal M, Farid A, Khan FU, Mirza B and Waheed MT (2019) Disease Status of Afghan Refugees and Migrants in Pakistan. Front. Public Health 7:185. doi: 10.3389/fpubh.2019.00185

\section{Disease Status of Afghan Refugees and Migrants in Pakistan}

\author{
Muhammad Suleman Malik', Muhammad Afzal ${ }^{2}$, Alveena Farid ${ }^{3}$, Fati Ullah Khan ${ }^{1}$, \\ Bushra Mirza ${ }^{1}$ and Mohammad Tahir Waheed ${ }^{1 *}$
}

${ }^{1}$ Department of Biochemistry, Faculty of Biological Sciences, Quaid-i-Azam University, Islamabad, Pakistan, ${ }^{2}$ Department of Animal Science, Faculty of Biological Sciences, Quaid-i-Azam University, Islamabad, Pakistan, ${ }^{3}$ Ayub Teaching Hospital, Abbottabad, Pakistan

World is facing the largest refugee crisis of its time due to continuously outgoing wars, conflicts and natural disasters. One of the important aspects of refugees and migrants is health. Till date, no comprehensive data was available related to health status of Afghan refugees and internally displaced persons (IDPs) in Pakistan. Here, we present health status for Afghan refugees for last seven years and for IDPs for 2-4 years. For Afghan refugees the data was provided by Commissionerate Afghan Refugee (CAR), Pakistan, whereas data for IDPs was collected from hospitals and Basic health units (BHUs) of different districts of Khyber Pakhtunkhwa namely Peshawar, Dera Ismail Khan and Bannu. Highest number of Afghan refugee's deaths occurred due to cardiovascular problems. Most prevalent reported infections were respiratory tract infections (48.05\%). Skin diseases and Diarrhea collectively affected $21.08 \%$ of Afghan refugees. Overall, disease burden was more in females than males in Afghan refugee's population. To the best of our knowledge, this is the first comprehensive report on health and disease status of Afghan refugees and IDPs in Pakistan.

Keywords: Afghan refugees, internally displaced people, Pakistan, disease status, healthcare, disease-related mortality

\section{INTRODUCTION}

Pakistan is a developing country, holding sixth largest population in the world with a number reaching $\sim 208$ million according to a recent census conducted by Pakistan Bureau of Statistics (1). Pakistan is ranked among low-middle income countries (LMIC) by World Bank (2), having $\sim 4 \$$ per day income (3). It is estimated that $39 \%$ of Pakistani population is living in multidimensional poverty (4), marked by several factors, mainly poor health, lack of education, less income, poor quality of work and threat of violence. Approximately, $65 \%$ of Pakistani population is residing in rural areas where health, hygiene and sanitation conditions are not very good compared to urban areas. These factors make the residing population at risk of various infections and diseases. Most migrants or refugees prefer to live in rural areas due to less costs of living. Also, in most cases, the camps arranged by the government for living of refugees lie in outskirts of urban areas. This increases the burden of already populated rural areas and thus incidence of diseases increases. Additionally, movement of people from one place to other serves as a source of dispersal of infections to new areas, where previously those infections were absent or less prevalent. 
Recently, United Nations High Commissioner for Refugees (UNHCR) reported that there were 22.5 million refugees at the end of the year 2016 around the world (5). This number may have been increased in 2017 due to number of new crisis that resulted in massive migration such as recent movement of Rohingya people from Myanmar to Bangladesh. As per this report (5), Pakistan was ranked as second-largest refugee hosting country (1.6 million) after Turkey (2.5 million). Around 2.3 million Afghan refugees came to Pakistan within years 19791982 as they fled from war with Soviet Union (6). In addition to influx of refugees, Pakistan has been facing the crises of internally displaced people (IDPs) from time to time because of military operations against terrorism and conflicts (7). Throughout the history, one of the major problems of humanity has been the migration especially for developing countries (8). Regardless of efforts that were made by World Health Organization (WHO), UNHCR, non-governmental organizations (NGOs) and other humanitarian organizations, basic needs of refugees such as housing, food and other social needs are often not met. One of the major problems that refugees face is accessibility to medical facilities and this situation becomes more critical when it comes to developing countries (9).

When refugees transit from non-endemic region to an endemic region, they are more prone to local diseases as compared to indigenous population, as they are not immune to native strains (10). The communicable and non-communicable disease burden is double on Pakistan as it is passing through epidemiological transition (11). A communicable disease is an infection that is transmissible to persons from animate or inanimate sources whereas non-communicable diseases (NCD: chronic diseases) have the tendency to be of long duration and are the aftereffect of a mix of different factors (genetic, physiological, environmental and behavioral) $(12,13)$. In Pakistan, $\sim 38 \%$ of deaths occur due to communicable, maternal, perinatal and nutritional conditions and non-communicable diseases accounts for $51 \%$ of total deaths whereas remaining $11 \%$ of deaths occur due to injuries (14). NCD includes diabetes, chronic respiratory diseases (CRD), cardiovascular diseases and cancer and risk factors associated with them (15).

Pakistan has been facing terrorism, economic problems, political instability, poverty and health problems from several decades (16-18). Among these problems, health has been a major issue. Pakistan is prone to disasters such as earthquakes, floods and drought (19). Due to continuously ongoing war in Afghanistan since last four decades, there has been constant influx of Afghan people to Pakistan for shelter, refuge and sometimes for business. Additionally, $\sim 1.8$ million Pakistani people were internally/temporarily displaced due to military operations against terrorism in 2015 (20). All these factors collectively affect the health status of afghan refugees and temporarily displaced persons and put indigenous population at risk. There has been lack of data regarding overall health status of afghan refugees and IDPs in Pakistan in recent past. This data is necessary for the Government and related-organizations to carryout health-care activities and target certain diseases. The main objective of this report was to collect the data and evaluate the disease status of the afghan refugees and IDPs in Pakistan based on the data collected from different areas/hospitals, government institutes within Pakistan and from online data available from January 2012 to December 2018. The data was processed through a database in MS Excel and represented in the form of graphs and narrations.

\section{METHODS}

\section{Data Collection}

Current study was aimed to evaluate the health status of the Afghan refugees and IDPs in Pakistan. Data for Afghan refugees was collected from Commissionerate Afghan Refugees (CAR). Khyber Pakhtunkhwa (KPK), Pakistan. Data provided by CAR covered 16 Basic Health Units (BHUs), One Sub Health Unit and Implementing Partners (IPs) from January 2012 to Dec 2018. Data comprised of demography, mortality and morbidity against different infectious and non-infectious diseases. In addition, maternity, vaccination and malarial status was also included in Afghan refugee's data. For collection of health record of internally displaced people (IDPs), we surveyed different districts of Khyber Pakhtunkhwa namely Peshawar, Dera Ismail Khan, Bannu, Lakki Marwat, and Tank as shown in Figure 1. Being neighboring areas of Federally Administered Tribal Areas (FATA), these districts contained most population of IDPs. We collected data of communicable and non-communicable diseases of IDPs' enrolled patients from different healthcare centers of IDPs' lodging districts. Data was collected from province KPK because it holds the largest population of Afghan refugees (62\%) and IDPs (21). However, there were some limitations, we were unable to collect reliable data of IDPs' health status from Tank and Lakki Marwat due to lack of reliable record in district health centers.

\section{RESULTS}

\section{Afghan Refugees Health Status Demography}

Figure 2 shows the demographic status of Afghan refugees for last 7 years. The Afghan refugees' population had $41 \%$ males and $41 \%$ females, with 1:1 ratio of male to female. Among them, $4 \%$ of population was under the age of 1 year and $14 \%$ between the age of 1-4 years. Rest of population was above the age of 5 years.

\section{Mortality and Causes of Mortality}

Most patients were males as compared to female and mortality rate was high in males as shown in the Table 1. The major factor for high mortality rate could be due to fact that males are more exposed to external environmental stresses as compared to Afghan females. Per every 1,000 afghan refugees total mortality rate in males was found to be 0.09 and among females it was 0.07 . Whereas, below 5 years of age, rate of mortality was 0.24 per 1,000. The main causes of mortality in Afghan refugees (Table 1) were cardiovascular disorders $(23.53 \%)$ and respiratory disorders (14.22\%). Among other causes of mortality were hepatitis $(2.75 \%)$, watery diarrhea $(1.61 \%)$, dysentery $(1.30 \%)$, typhoid $(0.74 \%)$, measles $(0.17 \%)$, and tuberculosis $(0.12 \%)$. 




FIGURE 1 | Map of Districts visited for collection of Data. The colored areas show the districts where most Afghan refugees and IDPs were located. KPK, Khyber Pakhtunkhwa province, province adjacent to Afghanistan.

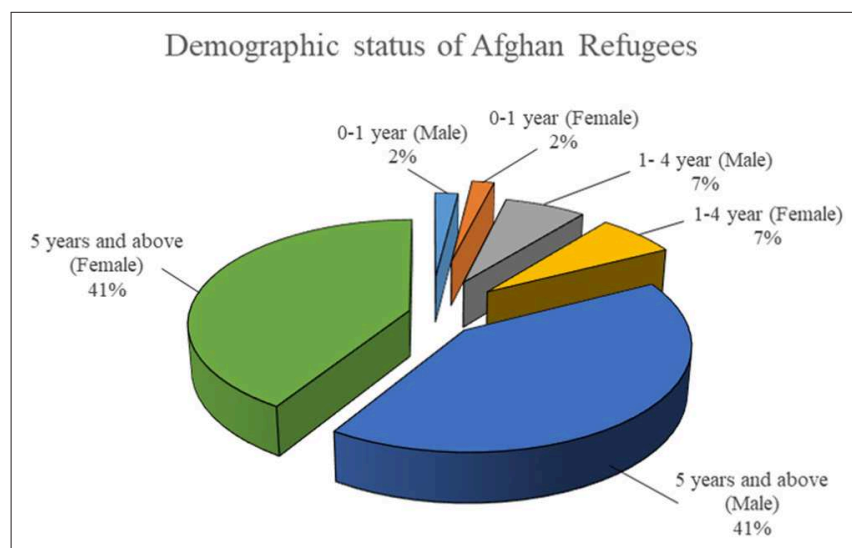

FIGURE 2 | Demographic status of Afghan refugees for year 2012 to 2018

\section{Morbidity}

About $49.12 \%$ of Afghan refugees were suffering from respiratory tract infections. Upper respiratory tract infections (URTI) incidence rate $(12.74 / 1000)$ was significantly high as compared to lower respiratory tract infections (LRTI) incidence rate $(3.42 / 1000)$. The incidence rates for diarrhea and dysentery were 3.49 and 1.26 out of 1000 afghan refugees, respectively. Skin diseases affected afghan refugees at a rate of 3.59 out of every 1000 refugees. Incidence rate for cardiovascular disorders among afghan refugees recorded was $0.95 / 1000$. Other diseases reported were typhoid $(0.25 / 1000$, measles $(0.005 / 1000)$, and reproductive tract infections $(0.94 / 1000)$. Out of 9530 Afghan refugees suffering from psychological disorders, 301 patients were referred to psychiatrist. Approximately $42.02 \%$ were male patients and 71.42 were female patients. Disease burden and morbidity with respect to age and gender is shown in Table 2.

\section{Maternal Health Status Among Afghan Refugees}

Table 3 shows the health status of mother and children among immigrants. Still birth ratio was 1.29 for 7 years (Jan 2012-Dec 2018). Crude birth rate reported among refugees was $2.51 / 1000$ population. Average Infant Mortality Rate (IMR: 0-1 years) recoded was 8.21 per 1000 live births. Neonatal Mortality Rate (NNMR) and Maternal Mortality Rate (MMR) reported were $2.33 / 1000$ births and 13.70 per 100,000 births, respectively.

\section{Vaccination in Afghan Refugees}

Detailed status of vaccination in Afghan refugees is summarized in Table 3. The refugees were vaccinated against Tuberculosis (BCG), Measles, Polio, DPT, Tetanus, Diphtheria, Pertussis (whooping cough). From 2012 to 2018, percentage coverage for BCG and measles was 87.31 and $100 \%$, respectively.

\section{Proportion of Afghan Refugees With Tuberculosis}

Tuberculosis (TB) was responsible for death of ten immigrants from year 2012 to 2018. Positive cases of TB were more in females as compared to males (54.72 and $45.28 \%$, respectively). 
TABLE 1 | Mortality and causes of mortality in Afghan refugees.

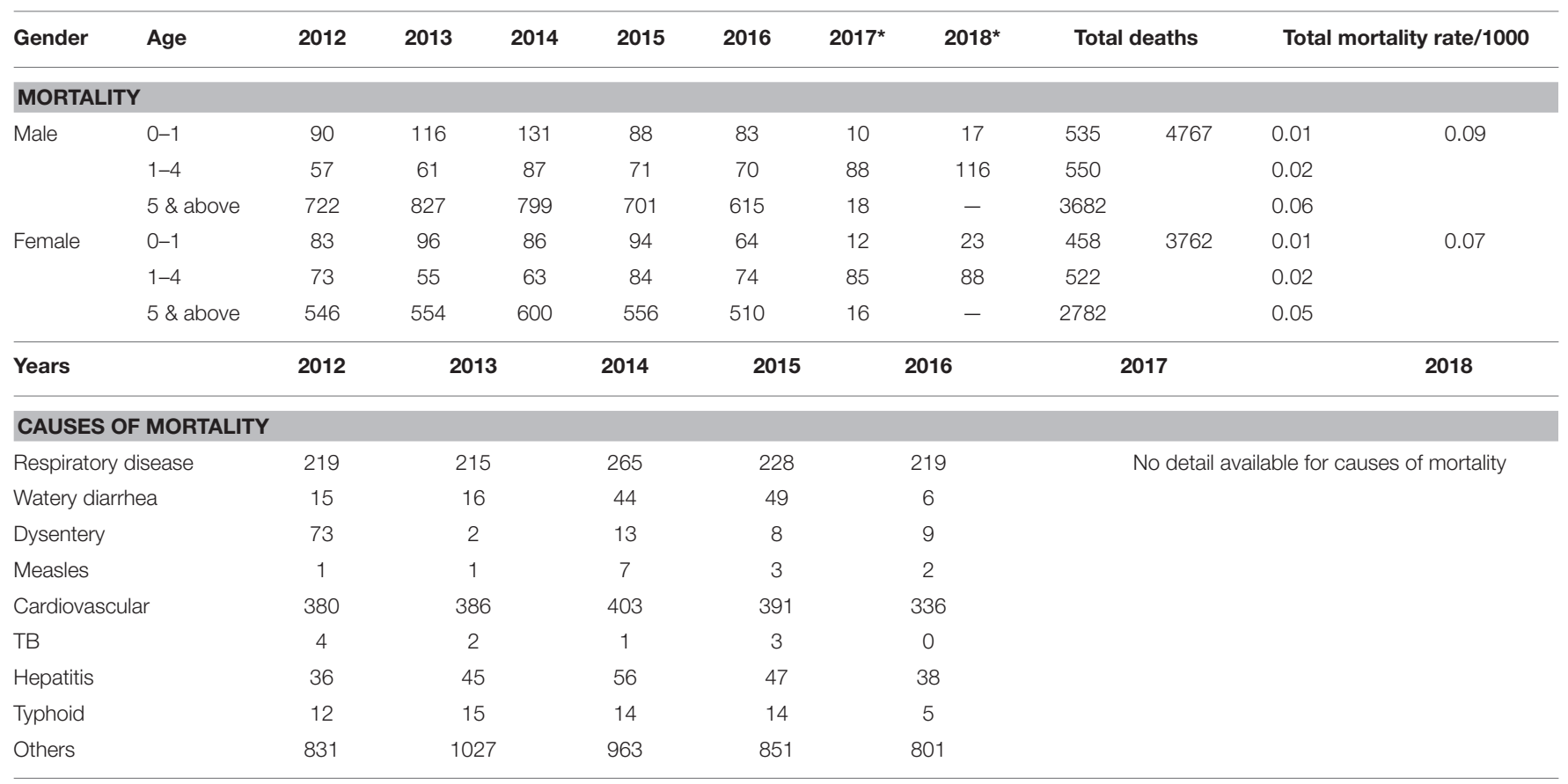

${ }^{\star} N G O$ 's record is absent.

Thirty-five cases of defaulters were reported among refugees and 29 cases reported for failure in treatment. Immigrants who successfully overcame TB by completing treatment were 207. Table 4 summarizes the TB status among Afghan refugees.

\section{Proportion of Afghan Refugees With Malaria}

Total of three deaths due to malaria were reported from year 2012 to 2018 among Afghan immigrants as shown in Table 4. Over-all, 10,710 positive cases of malaria were testified among refugees. The proportion of malaria infection was high in refugees older than 5 years $(81.37 \%)$ and in females $(60.91 \%)$. Most prevalent species in immigrants was $P$. vivax as compared to $P$. falciparum ( 96.15 and $2.01 \%$, respectively). Total 196 cases of mixed malaria were reported.

\section{Internally Displaced Persons (IDPs) Health Status}

Tables 5-7 summarizes the status of internally displaced people (IDPs) in three different districts namely Peshawar, Dera Ismail Khan and Bannu. Skin diseases were more common than other disorders/diseases in district Peshawar (3,248 cases) whereas respiratory infections were more common in District Dera Ismail Khan and Bannu (14142 and 9399 cases, respectively). Nineteen cases of polio were reported in district Peshawar in year 2015 and 346 IDPs were referred to psychiatrist. Total of 150 surgeries were performed in district Peshawar and 50 cases of jaundice were reported in district Dera Ismail Khan. Among cardiovascular disorders 2,685 cases (2 years) were reported in District Bannu and 20 cases (in 3 years) in district Peshawar. Two hundred and ninety-three female patients were treated with problems of gynecology. Overall, disease data, including other diseases, is given in Tables 5-7 for District Peshawar, Dera Ismail Khan and Bannu, respectively.

\section{DISCUSSION}

In the present study, we have collected data from those areas of Pakistan where there was a larger influx of afghan refugees and internally displaced people (IDPs). We have estimated the number refugees and IDPs with illnesses in these areas and assessed their disease status. To our knowledge, this is the first comprehensive report on the disease status of Afghan refugees and IDPs in Pakistan covering different disease and diseaserelated deaths.

Migration is centuries old phenomenon. People move to other places due to multiple factors such as economic reasons, agricultural crisis, political crisis, natural disasters, wars, and complex emergencies. Later three factors disturb the cultural and social life of migrants or refugees especially the poor ones more than any other factors do, which compels the people to migrate to other places. As the population of world increasing the more people are at risk to be affected by such events (22).

Pakistan has been a victim of terrorism, political and economic instability, and natural disasters such as floods, earthquakes and drought. Some of these factors directly affect the health of people in affected areas and cause displacement of people from one place to other. In addition, poverty, lack of education, poor health-care system and facilities makes people more vulnerable to diseases. More than half population of Pakistan lives in rural areas and is at more risk due to number of additional factors such 
TABLE 2 | Disease morbidity of Afghan refugees.

\begin{tabular}{|c|c|c|c|c|c|c|c|c|c|c|c|c|c|}
\hline \multicolumn{3}{|c|}{ Disease } & \multirow{2}{*}{$\begin{array}{c}2012 \\
144218\end{array}$} & \multirow{2}{*}{$\begin{array}{c}2013 \\
129574\end{array}$} & \multirow{2}{*}{$\begin{array}{c}2014 \\
154373\end{array}$} & \multirow{2}{*}{$\begin{array}{c}2015 \\
179813\end{array}$} & \multirow{2}{*}{\multicolumn{2}{|c|}{$\begin{array}{c}2016 \\
137007\end{array}$}} & & \multirow{2}{*}{$\begin{array}{l}2017 \\
6873\end{array}$} & \multirow{2}{*}{\multicolumn{3}{|c|}{$\begin{array}{r}2018 \\
1009\end{array}$}} \\
\hline \multirow[t]{2}{*}{ URTI } & & Morbidity & & & & & & & & & & & \\
\hline & & Incidence & 16.06 & 14.82 & 17.35 & 21.06 & & 16.75 & & 2.73 & & 0.40 & \\
\hline \multirow[t]{2}{*}{ LRTI } & & Morbidity & 46745 & 30101 & 32738 & 50587 & & 39862 & & 1962 & & 64 & \\
\hline & & Incidence & 5.20 & 3.44 & 3.68 & 5.92 & & 4.87 & & 0.78 & & 0.03 & \\
\hline \multirow{2}{*}{\multicolumn{2}{|c|}{ Diarrhea }} & Morbidity & 34253 & 35155 & 45783 & 44963 & & 40015 & & 2521 & & 746 & \\
\hline & & Incidence & 3.81 & 4.02 & 5.15 & 5.27 & & 4.89 & & 1.00 & & 0.29 & \\
\hline \multirow{2}{*}{\multicolumn{2}{|c|}{ Dysentery }} & Morbidity & 16423 & 11244 & 12584 & 16744 & & 13740 & & 1341 & & 212 & \\
\hline & & Incidence & 1.83 & 1.29 & 1.41 & 1.96 & & 1.68 & & 0.53 & & 0.08 & \\
\hline \multirow{2}{*}{\multicolumn{2}{|c|}{ Skin diseases }} & Morbidity & 38309 & 39681 & 40316 & 47692 & & 42908 & & 1889 & & 510 & \\
\hline & & Incidence & 4.27 & 4.54 & 4.53 & 5.58 & & 5.25 & & 0.75 & & 0.20 & \\
\hline \multirow{2}{*}{\multicolumn{2}{|c|}{ Typhoid }} & Morbidity & 1126 & 1575 & 1739 & 2931 & & 3124 & & - & & - & \\
\hline & & Incidence & 0.13 & 0.18 & 0.20 & 0.34 & & 0.38 & & - & & - & \\
\hline \multirow{2}{*}{\multicolumn{2}{|c|}{ Measles }} & Morbidity & 86 & 74 & 14 & 21 & & 12 & & - & & - & \\
\hline & & Incidence & 0.01 & 0.01 & 0.002 & 0.002 & & 0.001 & & - & & - & \\
\hline \multirow{2}{*}{\multicolumn{2}{|c|}{ Reproductive tract infection }} & Morbidity & 6044 & 6480 & 7079 & 6507 & & 6816 & & - & & 7051 & \\
\hline & & Incidence & 0.67 & 0.74 & 0.80 & 0.76 & & 0.83 & & - & & 2.78 & \\
\hline \multirow{2}{*}{\multicolumn{2}{|c|}{ Cardiovascular }} & Morbidity & 9168 & 8587 & 9342 & 10990 & & 9338 & & - & & 3025 & \\
\hline & & Incidence & 1.02 & 0.98 & 1.05 & 1.29 & & 1.14 & & - & & 1.19 & \\
\hline \multirow{2}{*}{\multicolumn{2}{|c|}{ Psychological disorder }} & Morbidity & 2121 & 2028 & 1544 & 2027 & & 1810 & & - & & - & \\
\hline & & Incidence & 0.24 & 0.23 & 0.17 & 0.24 & & 0.22 & & - & & - & \\
\hline \multicolumn{3}{|c|}{ Referred to psychiatric } & 24 & 67 & 58 & 78 & & 74 & & - & & - & \\
\hline \multirow{2}{*}{\multicolumn{2}{|c|}{ Others }} & Morbidity & 57522 & 82358 & 87845 & 82797 & & 88924 & & 13765 & & - & \\
\hline & & Incidence & 6.40 & 9.42 & 9.87 & 9.70 & & 10.87 & & 5.48 & & - & \\
\hline \multicolumn{4}{|c|}{ Gender/Age/Year } & 2012 & 2013 & 2014 & 2015 & & 2016 & & $2017^{*}$ & & $2018^{\star}$ \\
\hline \multicolumn{14}{|c|}{ MORBIDITY WITH RESPECT TO GENDER AND AGE } \\
\hline \multirow[t]{4}{*}{ Gender } & Male & Morbidity & & 166997 & 153383 & 170,135 & 206664 & & 167532 & & 11253 & & 3038 \\
\hline & & $\%$ Male p & & 48.54 & 45.06 & 43.89 & 47.20 & & 44.27 & & 41.12 & & 24.08 \\
\hline & Female & Morbidity & & 298489 & 268198 & 300,977 & 365931 & & 298750 & & 17098 & & 4035 \\
\hline & & $\%$ Female & & 86.75 & 78.79 & 77.65 & 83.58 & & 78.94 & & 62.48 & & 31.98 \\
\hline \multirow[t]{7}{*}{ Age (years) } & $0-1$ & Morbidity & & 54857 & 45412 & 54077 & 66423 & & 48945 & & 3461 & & 728 \\
\hline & & $\%$ 0-1 pa & & 15.41 & 13.09 & 13.75 & 14.92 & & 12.76 & & 39.69 & & 5.77 \\
\hline & $1-4$ & Morbidity & & 118968 & 106185 & 126208 & 151940 & & 123898 & & 7769 & & 1432 \\
\hline & & $\%$ 1-4 pa & & 33.42 & 30.61 & 32.08 & 34.14 & & 32.30 & & 60.31 & & 11.35 \\
\hline & $5 \&$ Above & Morbidity & & 291661 & 269984 & 290827 & 254232 & & 293439 & & 17121 & & 4913 \\
\hline & & $\% 5 \& a b c$ & ients & 81.92 & 77.84 & 73.93 & 57.12 & & 76.50 & & 12.21 & & 38.94 \\
\hline & Repea & & & 11953 & 6443 & 5758 & 7,237 & & 5095 & & 984 & & 0 \\
\hline
\end{tabular}

URTI, upper respiratory tract infection; LRTI, lower respiratory tract infection. *NGO's record is absent.

as non-affordability/non-availability of medicines due to less income, poor sanitation and a smaller number of health care professionals.

A constant war in neighboring Afghanistan since last four decades has directly impacted Pakistan in many ways. Massive migration of people from Afghanistan had an economic impact on an already developing country. Time to time ongoing operations in the border areas result in the displacement of people, largely to neighboring rural areas. This increases the health-related risks of indigenous population. Conversely, migrating people are also at risk to local infections. Till date, no collective data was available regarding disease status of Afghan refugees and IDPs residing in Pakistan in neighboring areas of conflict.

It is often problematic to collect data from remote areas and near-border areas due to military operations and road conditions. Healthcare to indigenous and refugees/IDPs in these areas is provided by local hospitals, military healthcare professionals, NGOs, Government-based Basic Health Units (BHUs) and World Health Organization (WHO). It is sometimes very difficult to collect data from all these sources and put it in one form to assess the number of patients and prevalent infections and diseases. In the present study, we have collected data from most of those areas where refugee's 
TABLE 3 | Mother and child health along with vaccination status among Afghan refugees.

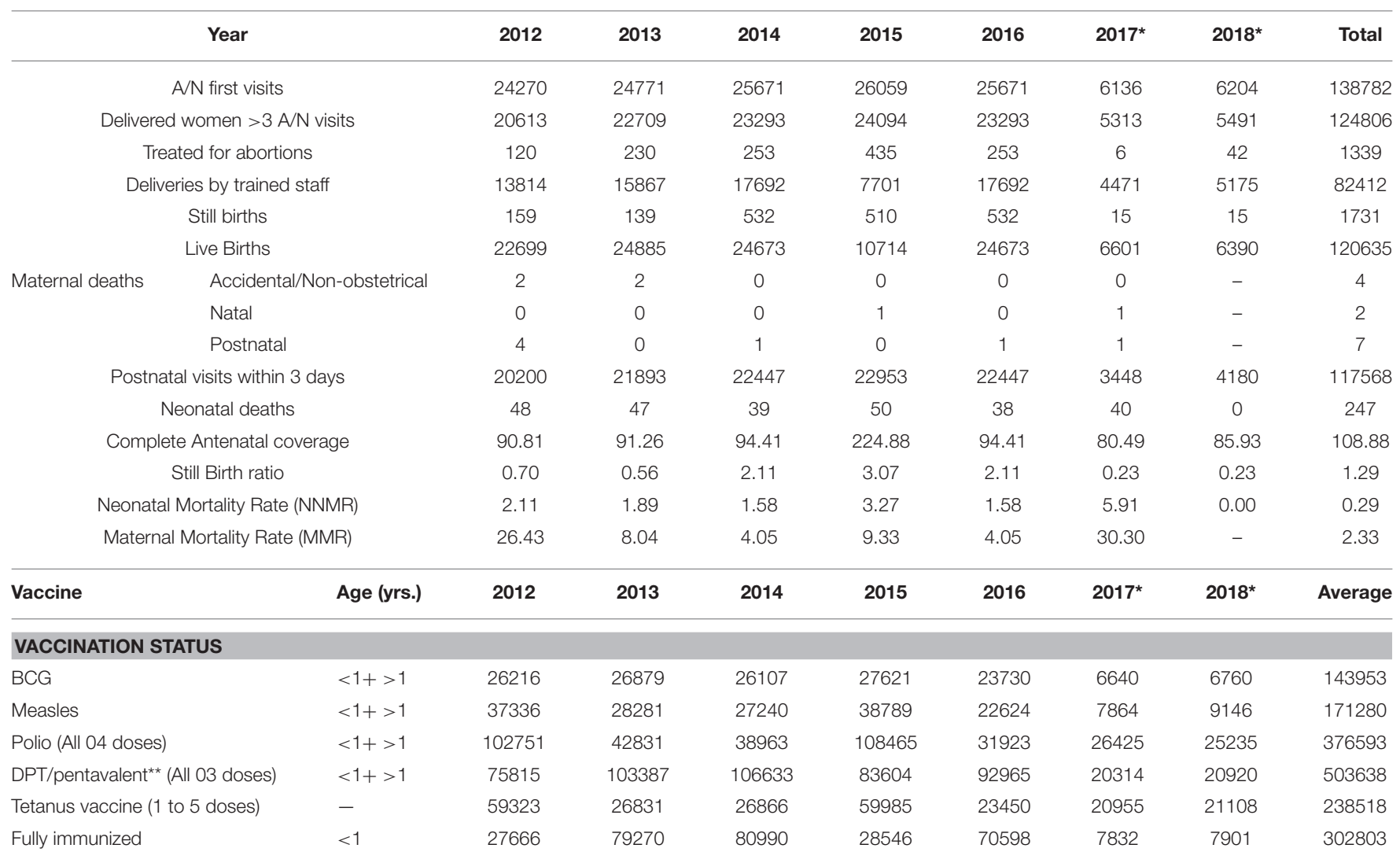

*NGO's record is absent. **Pentavalent vaccination done in year 2017 and 2018.

influx was highest. Also, these areas were linked to tribal areas (near Afghanistan border) where IDPs were temporarily placed. These areas included districts Peshawar, Dera Ismail Khan, Bannu, Lakki Marwat and Tank from the province of Khyber Pakhtunkhwa, adjacent to Afghanistan. Data from some NGOs, who had discontinued their operation in these areas, could not be retrieved.

We observed 1:1 male to female ration in the present study. Previously, UNHCR survey (23) showed that there were 103 males per 100 females, which is approximately equal to $1: 1$. During migration, it is expected that a significant number of deaths will occurs whether the migration is done forcefully or voluntarily (22). However, we observed a lower mortality rate. A lower mortality ratio has also been observed in some migrant populations, for example, overall mortality among Vietnamese refugees of England and Wales was very low as it was expected: for males the all-cause standardized mortality ratio was 64 whereas for females it was 56 (24). A previous finding shows that the crude deaths for refugees in Pakistan was 10/10,000 refugees between the year 1998 to 2012 (25). In our study the mortality rate was high for males $(0.09 / 1000)$ as compared to females $(0.07 / 1000)$ among afghan refugees. A lower mortality rate could be due to constant health support provided by Government, NGOs, and organizations like WHO.
Risk of various health conditions, like cardiovascular diseases and diabetes, is expected to be more among refugees due to starvation $(26,27)$. Marshal et al. (28) reported that risk for cardiovascular diseases is more in Cambodian refugees, but proposed an extensive study. In a 2012 report, 10\% of afghan refugees in Iran were heart patients (29). In our study, the total rate of cardiac patients is $6.67 / 1000$ in afghan refugees in Pakistan. Stress is the key factor whether the migration is done forcefully, planned or voluntary because it involves the breaking of relation with family, friends, culture and social interactions and to settlement in new and different environment.

We observed rate of psychological disturbances in afghan refugees equivalent to 0.22 per 1,000 persons. There are number of socio-economic factors that could lead to psychological disturbances. Again, males are more prone to such factors and hence are expected to suffer more with psychological problems. One of such factor is language that could be related to mental health (22). However, in case of Afghan refugees in Pakistan, the language may not be a major problem for most of afghan refugees because among them $82 \%$ were of Pashtun ethnicity, while rest included Tajiks, Uzbeks, and Persians (23).

Among migrants or refugees, the communicable diseases are not the only the health-related issue which affects them most. Especially the reproductive health of female refugees is of importance too that has to be reported (22). Due to 
TABLE 4 | Tuberculosis and malarial status among Afghan Refugees.

\begin{tabular}{|c|c|c|c|c|c|c|c|c|c|}
\hline \multicolumn{2}{|l|}{ Years } & 2012 & 2013 & 2014 & 2015 & 2016 & $2017^{*}$ & $2018^{*}$ & Total \\
\hline \multicolumn{10}{|c|}{ TUBERCULOSIS STATUS } \\
\hline \multicolumn{2}{|c|}{ Total new TB cases } & 156 & 98 & 138 & 149 & & \multicolumn{2}{|c|}{ No case reported } & 541 \\
\hline \multicolumn{2}{|c|}{ New sputum positive } & 60 & 35 & 35 & 29 & & & & 159 \\
\hline \multicolumn{2}{|c|}{ New sputum negative } & 96 & 63 & 103 & 117 & & & & 379 \\
\hline \multicolumn{2}{|c|}{ New sputum positive male } & 22 & 16 & 10 & 24 & & & & 72 \\
\hline \multicolumn{2}{|c|}{ New sputum positive female } & 38 & 19 & 25 & 5 & & & & 87 \\
\hline \multicolumn{2}{|c|}{ Patients cured [last sputum clear] (a) } & 53 & 30 & 24 & 13 & & & & 120 \\
\hline \multicolumn{2}{|c|}{ Treatment completed (b) } & 73 & 55 & 51 & 28 & & & & 207 \\
\hline \multicolumn{2}{|c|}{ Patients died (c) } & 4 & 2 & 1 & 19 & & & & 26 \\
\hline \multicolumn{2}{|c|}{ Failure of treatment $(d)$} & 7 & 0 & 21 & 1 & & & & 29 \\
\hline \multicolumn{2}{|c|}{ Defaulters(e) } & 4 & 8 & 8 & 15 & & & & 35 \\
\hline \multicolumn{2}{|c|}{ Transferred out(f) } & 11 & 12 & 130 & 0 & & & & 153 \\
\hline \multicolumn{2}{|c|}{ Total patients evaluated $(a+b+c+d+e+f)$} & 152 & 107 & 235 & 76 & & & & 570 \\
\hline \multicolumn{10}{|c|}{ MALARIAL STATUS } \\
\hline \multicolumn{2}{|c|}{ Deaths due to Malaria } & 2 & 0 & 1 & 0 & 0 & - & - & 3 \\
\hline \multicolumn{2}{|r|}{ Total positive } & 2367 & 1946 & 2294 & 2592 & 1511 & 396 & 474 & 11580 \\
\hline \multirow[t]{2}{*}{ Gender } & Male cases & 931 & 796 & 820 & 1025 & 614 & \multicolumn{2}{|c|}{ No details available } & 5056 \\
\hline & Female cases & 1436 & 1150 & 1474 & 1567 & 897 & & & 6524 \\
\hline \multirow[t]{3}{*}{ Age (yrs.) } & $0-1$ & 54 & 38 & 37 & 40 & 19 & & & 188 \\
\hline & $1-4$ & 380 & 287 & 332 & 533 & 275 & & & 1807 \\
\hline & $5 \&$ above & 1933 & 1621 & 1925 & 2019 & 1217 & & & 8715 \\
\hline \multirow[t]{3}{*}{ Species } & P. falciparum & 38 & 8 & 114 & 45 & 11 & & & 216 \\
\hline & P. Vivax & 2242 & 1840 & 2180 & 2538 & 1498 & & & 10298 \\
\hline & Mixed malaria & 87 & 98 & 0 & 9 & 2 & & & 196 \\
\hline
\end{tabular}

*NGO's record is absent.

pregnancy or child birth related complications, deaths of more than half million women occur each year (30). In this light, aim of UN fifth Millennium Development Goal was kept to improve the maternal health (31). In Afghanistan, the risk of maternal death has been too high in the world. For instance, in city of Kabul, the maternal mortality was $418 / 100,000$ live births during 2002, which significantly decreased by $60 \%$ in the year 2011 that is $166 / 100,000$ live births. In 2011, the health facilities were increased by Government. In a recent study, the perinatal death rate among Afghanis was 29 per 1000 live births in Kabul, Afghanistan (32). Providing training to staff related to reproductive health plays important role in decreasing the mortality rate and morbidity related to mother and child (33). A survey done during the year 1999 to 2000 reported that in refugee camps of district Hangu (Khyber Pakhtunkhwa) the health condition for the women was poor. International Rescue Committee (IRC) trained the staff and increased the knowledge in the community regarding maternal health. As a result the maternal mortality rate decreased to 102 per 100,000 live births in 2004 and 67\% of deliveries handles by skilled personnel in 2007 (34). Our data shows that $80 \%$ of deliveries were handled by trained staff in 2018 whereas average perinatal deaths from year 2012-2013 rate was $17.30 / 1000$ live births. The mortality rate for infants and child as compared to Pakistan among afghan refugees were low in year 2011 (23). The perinatal deaths during our study timeline was lower than that of Afghanis in Kabul during the year 2011, which may be due to better medical facilities in Pakistan than Afghanistan.

Vaccination of children among refugees in Iran has been lower than the Iranian children due to lack of parental attention and lack of awareness toward such programs (35). Among afghan refugees in Pakistan, only one case of Polio was reported in June of 2016 in 2-year-old refusal child refugee who returned from Afghanistan (36). Afghanistan and Pakistan are only two countries where Polio remains endemic (37). The percentage coverage of immunization in children among Afghan refugees was 100\% from 2012 to 2018. It was possible due to the efforts of Pakistan Government immunization program.

Pakistan is among top five countries having high rate of TB (38). In 2011, the National Tuberculosis Control Programme (NTP) achieved 64\% detection rate for tuberculosis cases in Pakistan (39). In 2000, the rate of tuberculosis in newly arrived refugees (504 per 100,000 person) in United States was significantly high than its national rate (40). The Jordan National TB Program reported 56 cases among Syrian refugees including the 3 multidrug resistant cases (41). We report total of 541 new 
TABLE 5 | Health status of IDPs in Peshawar.

\begin{tabular}{|c|c|c|c|c|}
\hline Year & $2014^{*}$ & $2015^{\star \star}$ & $2016^{\star \star \star}$ & Total \\
\hline Cardiovascular disorders & 8 & 12 & 0 & 20 \\
\hline Causality & 406 & 1533 & 381 & 2320 \\
\hline Dental & 8 & 98 & 0 & 106 \\
\hline ENT & 41 & 183 & 0 & 224 \\
\hline EYE & 79 & 776 & 0 & 855 \\
\hline Gynecology & 41 & 252 & 0 & 293 \\
\hline Medicine & 132 & 466 & 1 & 599 \\
\hline Nephrology & 15 & 425 & 0 & 440 \\
\hline Orthopedic & 131 & 1121 & 0 & 1252 \\
\hline Pediatrics & 144 & 624 & 0 & 768 \\
\hline Pediatric surgery & 3 & 12 & 0 & 15 \\
\hline Plastic surgery & 1 & 44 & 0 & 45 \\
\hline Psychiatry & 11 & 335 & 0 & 346 \\
\hline Skin diseases & 120 & 3128 & 0 & 3248 \\
\hline Surgical & 27 & 123 & 0 & 150 \\
\hline Polio & - & 19 & 0 & 19 \\
\hline Respiratory tract infections & 12 & 30 & 0 & 42 \\
\hline
\end{tabular}

${ }^{\star}$ Record of 3 months. ${ }^{\star \star}$ Record of 6 months. ${ }^{* \star}$ Record of 7 months.

TABLE 6 | Health status IDPs in Dera Ismail Khan.

\begin{tabular}{|c|c|c|c|c|c|}
\hline & Year & $2014^{\star}$ & 2015 & 2016 & $2017^{\star *}$ \\
\hline \multirow[t]{3}{*}{ Total no patients } & Male & 9670 & 4764 & 1679 & 921 \\
\hline & Female & 7126 & 8975 & 3360 & 1841 \\
\hline & Children & 6834 & 11421 & 4293 & 2352 \\
\hline \multirow[t]{7}{*}{ Common illnesses } & G. I. diseases & 2156 & 2204 & 905 & 496 \\
\hline & $\begin{array}{l}\text { Acute respiratory } \\
\text { infection }\end{array}$ & 3036 & 6776 & 2797 & 1533 \\
\hline & Skin diseases & 3306 & 1800 & 737 & 404 \\
\hline & $\begin{array}{l}\text { Vaccine preventable } \\
\text { diseases }\end{array}$ & 1286 & 1120 & 457 & 251 \\
\hline & Fever & 6247 & 6636 & 2735 & 1498 \\
\hline & Jaundice & 20 & 16 & 9 & 5 \\
\hline & Any other & 5709 & 5240 & 1224 & 670 \\
\hline \multirow[t]{5}{*}{ Pregnancy care } & Ante natal & 1013 & 816 & 335 & 184 \\
\hline & Natal & 77 & 16 & 6 & 3 \\
\hline & Post natal & 752 & 536 & 127 & 70 \\
\hline & Injury & 10 & 10 & - & - \\
\hline & Deaths & 3 & 3 & - & - \\
\hline
\end{tabular}

${ }^{*}$ Record Available for 7 months. ${ }^{* \star}$ Record Available for 6 months.

TB cases in Afghan refugees during years 2012-2015, whereas no case has been reported between 2016 to 2018.

Many parts of Khyber Pakhtunkhwa and Afghanistan are malarial endemic regions (42). Additionally, malarial control remains challenging as it develops resistance against insecticides and antimalarials in use. Migration of 3 million afghan refugees to Pakistan were vulnerable because they settled in malaria endemic region and non-immune to Anopheline breeding (42). In our study, total of 10710 malarial cases were reported from 2012 to 2018 with total of 3 deaths from malaria. P. Vivax
TABLE 7 | Health status of IDPs in Bannu.

\begin{tabular}{llcc}
\hline & Year & $\mathbf{2 0 1 4}$ & $\mathbf{2 0 1 5}$ \\
\hline Total no patients & Male & 8160 & 11665 \\
& Female & 6759 & 9747 \\
& Children & 5559 & 7807 \\
Common illnesses & Cardiovascular disorders & 1104 & 1581 \\
& ENT & 2111 & 2999 \\
& Eye infections & 3004 & 4286 \\
& Neural surgeries & 2141 & 3063 \\
& Orthopedic & 3341 & 4768 \\
& Pediatrics surgery & 628 & 884 \\
& Psychiatric referrals & 1361 & 1947 \\
& Respiratory tract infections & 3870 & 5529 \\
& Skin disease & 1934 & 2756 \\
& Urinary tract infections & 984 & 1406 \\
Pregnancy care & Ante natal & 4368 & 1163 \\
& Natal & 642 & 1195 \\
& Post natal & 247 & 1371 \\
& Injury & 10 & 2 \\
& Deaths & 15 & 20 \\
\hline
\end{tabular}

was most prevalent in these reported cases. Surprisingly, only three malaria-related deaths were reported in 7 years period, although number of positive cases was high. This may be due to underreporting of death cause and actual number could be high (42). Overall, the number of diseased persons and deaths could be well high as many cases remain unreported in resource poor settings.

According to UNHCR, Pakistan was ranked second-largest country in terms of hosting refugees. The number reported for Afghan refugees by UNHCR was 1.6 million (5). In the same report UNHCR reported $\sim 1.1$ million IDPs, which according to Internal Displacement Monitoring Center was 1.8 million (20). In total, it makes the total population of migrants to 3.4 million, which makes Pakistan by far the largest migrant-hosting country in the world, compared to Turkey with 2.5 million refugee's population (5).

\section{CONCLUSIONS}

In the present report, disease status and disease-related deaths of Afghan refugees for past 7 years is presented. For IDPs, 2-4 years data is given. This data would be helpful to develop policies related to healthcare of refugees and migrants. Further, based on the available numbers, Pakistan can be considered as the country hosting the world's largest migrant population and displaced people.

\section{DATA AVAILABILITY}

The raw data supporting the conclusions of this manuscript will be made available by the authors, without undue reservation, to any qualified researcher. 


\section{AUTHOR CONTRIBUTIONS}

$\mathrm{MW}, \mathrm{BM}$, and $\mathrm{MM}$ conceived the study design, prepared, and finalized the manuscript. MM, FK, AF, and MA collected and analyzed the data. All authors have read and approved the final version of manuscript.

\section{REFERENCES}

1. Pakistan Bureau of Statistics. Provisional Summary Results of Census, 2017 (2017). Available online at: http://www.pbscensus.gov.pk/sites/default/files/ Population_Results.pdf (accessed August 29, 2017).

2. World Bank. Lower Middle Income Data (2016). Available online at: https:// data.worldbank.org/income-level/lower-middle-income (accessed August 20, 2017).

3. World Bank. GDP per Capita (current US\$)|Data (2016). Available online at: https://data.worldbank.org/indicator/NY.GDP.PCAP.CD?locations=PK (accessed August 20, 2017).

4. United Nations High Commissioner for Refugees (UNHCR). Pakistan's New Poverty Index Reveals That 4 out of 10 Pakistanis Live in Multidimensional Poverty|UNDP in Pakistan. (2016) Available online at: http://www.pk. undp.org/content/pakistan/en/home/presscenter/pressreleases/2016/06/20/ pakistan-s-new-poverty-index-reveals- that-4-out-of-10-pakistanis-live-inmultidimensional-poverty.html (accessed August 20, 2017).

5. United Nations High Commissioner for Refugees (UNHCR). UNHCR - Global Trends: Forced Displacement in 2016. (2016) Available online at: https://www.unhcr.org/statistics/unhcrstats/5943e8a34/global-trendsforced-displacement-2016.html (accessed August 10, 2017).

6. Kronenfeld DA. Afghan refugees in Pakistan: not all refugees, not always in Pakistan, not necessarily Afghan? J Refug Stud. (2008) 21:43-63. doi: $10.1093 /$ jrs/fem048

7. Khan ZA. Military operations in FATA and PATA: implications for Pakistan. Strateg Stud. (2012) 31:129-46.

8. Sari B, Koçak H, Çalişkan C. Syrian refugees in turkey, life conditions. Prehosp Disaster Med. (2017) 32:S81. doi: 10.1017/S1049023X17002126

9. Abou-Saleh MT, Christodoulou GN. Mental health of refugees: global perspectives. BJPsych Int. (2016) 13:79-81. doi: 10.1192/S2056474000 001379

10. Toole MJ, Waldman RJ. Prevention of excess mortality in refugee and displaced populations in developing countries. JAMA. (1990) 263:3296-302. doi: 10.1001/jama.1990.03440240086021

11. Lopez AD, Mathers CD, Ezzati M, Jamison DT, Murray CJ. Global and regional burden of disease and risk factors, 2001: systematic analysis of population health datao title. Lancet. (2006) 367:1747-57. doi: 10.1016/S0140-6736(06)68770-9

12. Webber R. Communicable Diseases: A Global Perspective (2016). Available online at: https://books.google.com.pk/books?hl=en\& $\mathrm{lr}=$ \&id $=$ wLEtDAAAQBAJ\&oi $=$ fnd \&pg $=$ PR3\&dq=Communicable + diseases:+a+global+perspective.+4th+ed.+Cambridge:+Centre+for+ Agriculture+and+Biosciences+International\%3B+\&ots=KYSo79VFuD\& sig=5bK3neyjtL4NgbsOS_8dMmLfKUw (accessed August 23, 2017).

13. World Health Organization (WHO). Noncommunicable Diseases (2017). Available online at: https://www.who.int/news-room/fact-sheets/detail/ noncommunicable-diseases (accessed August 20, 2017).

14. World Health Organization. Noncommunicable Diseases Country Profiles 2014. Geneva: World Health Organization (2014).

15. Nishtar S. NAP-NCD atlas: national action plan for prevention and control of noncommunicable diseases and health promotion in Pakistan. Prevent Control. (2005) 2:95-102. doi: 10.1016/j.precon.2006.10.002

16. Malik S, Hayat M, Of MH-IRJ, 2010 U. External Debt and Economic Growth: Empirical Evidence From Pakistan. Researchgate.net. Available online at: https://www.researchgate.net/profile/Shahnawaz_Malik/publication/ 260321284_External_Debt_and_Economic_Growth_Empirical_Evidence_ from_Pakistan/links/55b75d5e08ae9289a08be260/External-Debt-and-

\section{ACKNOWLEDGMENTS}

Authors acknowledge the Commissionerate Afghan Refugees (CAR) for providing data related to Afghan refugees. We are thankful to all hospitals and BHU staff for their cooperation in data collection.

Economic-Growth-Empirical-Evidence-from-Pakistan.pdf (accessed August 22, 2017).

17. Masood MT, Shah F. Dilemma of third world countries-problems facing pakistan energy crisis a case-in-point. Int J Bus Manag. (2012) 7:231. doi: 10.5539/ijbm.v7n5p231

18. Michael S. Terrorism a socio-economic and political phenomenon with special reference to Pakistan. J Manag Soc Sci. (2007) 3:35-46. doi: 10.1016/S0181-5512(07)74025-1

19. Sayed SA, González PA. Flood disaster profile of Pakistan: a review. Sci J Public Heal. (2014) 2:144-9. doi: 10.11648/j.sjph.20140203.11

20. Internal Displacement Monitoring Centre (IDMC). Pakistan IDP Figures Analysis. (2015) Available online at: http://www.internal-displacement.org/ south-and-south-east-asia/pakistan/figures-analysis (accessed November 17, 2017).

21. United Nations Development Program (UNDP). 2015-2017 Protection Strategy Pakistan. (2015) Available online at: http://unhcrpk.org/wpcontent/uploads/.../2015-2017-Protection-Strategy-External.docx (accessed November 28, 2017).

22. Carballo M, Nerukar A. Migration, refugees, and health risks. Emerg Infect Dis. (2001) 7:556. doi: 10.3201/eid0707.017733

23. UNHCR. Population Profiling, Verification and Response Survey of Afghans in Pakistan 2011. (2012) Available online at: http://unhcrpk.org/wp-content/ uploads/2018/05/Population-Profiling-Verification-and-Response-Surveyof-Afghans-in-Pakistan.pdf (accessed June 24, 2019).

24. Swerdlow AJ. Mortality and cancer incidence in Vietnamese refugees in England and Wales: a follow-up study. Int J Epidemiol. (1991) 20:13-19. doi: $10.1093 /$ ije/20.1.13

25. Heudtlass P, Speybroeck N, Guha-Sapir D. Excess mortality in refugees, internally displaced persons and resident populations in complex humanitarian emergencies (1998-2012)-insights from operational data. Confl Health. (2016) 10:15. doi: 10.1186/s13031-016-0082-9

26. Sparén $P$, Vågerö $D$, Shestov DB, Plavinskaja S, Parfenova N, Hoptiar V, Paturot D, Galanti MR. Long term mortality after severe starvation during the siege of Leningrad: prospective cohort study. BMJ. (2004) 328:11. doi: 10.1136/bmj.37942.603970.9A

27. Huang C, Li Z, Wang M, Martorell R. Early life exposure to the 19591961 Chinese famine has long-term health consequences. J Nutr. (2010) 140:1874-8. doi: 10.3945/jn.110.121293

28. Marshall GN, Schell TL, Wong EC, Berthold SM, Hambarsoomian K, Elliott MN, Bardenheier BH, Gregg EW. Diabetes and cardiovascular disease risk in Cambodian refugees. J Immigr Minor Heal. (2016) 18:110-7. doi: 10.1007/s10903-014-0142-4

29. Otoukesh S, Mojtahedzadeh M, Sherzai D, Behazin A, Bazargan-Hejazi S, Bazargan M. A retrospective study of demographic parameters and major health referrals among Afghan refugees in Iran. Int J Equity Health. (2012) 11:82. doi: 10.1186/1475-9276-11-82

30. United Nation. The Millennium Development Goals Report (2007). Available online at: https://www.un.org/millenniumgoals/pdf/mdg2007.pdf (accessed June 24, 2019).

31. Bashour H, Abdulsalam A, Jabr A, Cheikha S, Tabbaa M, Lahham M, Dihman R, Khadra M, Campbell OMR. Maternal mortality in Syria: causes, contributing factors and preventability. Trop Med Int Heal. (2009) 14:1122-7. doi: $10.1111 /$ j.1365-3156.2009.02343.x

32. Bartlett L, LeFevre A, Zimmerman L, Saeedzai SA, Turkmani S, Zabih W, et al. Progress and inequities in maternal mortality in Afghanistan (RAMOSII): a retrospective observational study. Lancet Glob Heal. (2017) 5:e545-55. doi: 10.1016/S2214-109X(17)30139-0 
33. Getachew F, Kassa GM, Ayana M, Amsalu E. Knowledge of direct obstetric causes of maternal mortality and associated factors among reproductive age women in aneded woreda, northwest Ethiopia; a crosssectional study. Pan Afr Med J. (2017) 27:32. doi: 10.11604/pamj.2017.27.32. 10274

34. Purdin S, Khan T, Saucier R. Reducing maternal mortality among Afghan refugees in Pakistan. Int J Gynecol Obstet. (2009) 105:82-5. doi: 10.1016/j.ijgo.2008.12.021

35. Zahraei SM, Eshrati B, Gouya MM. Is there still an immunity gap in highlevel national immunization coverage, Iran? Arch Iran Med. (2014) 17: 698-701.

36. World Health Organization Regional Office for the Eastern Mediterranean. Report on the Technical Consultation on Poliomyelitis Eradication in Pakistan, Islamabad (2016). Available online at: http://www.who.int/iris/handle/10665/ 252828 (accessed June 24, 2019).

37. World Health Organization (WHO). A Guide to Introducing Inactivated Poliomyelitis Vaccine Based on the Polio Eradication \& Endgame Strategic Plan 2013-2018 (2018). Available online at: http://www.who.int/immunization/ diseases/poliomyelitis/endgame_objective2/inactivated_polio_vaccine/ Introduction_Guide.pdf?ua=1 (accessed June 24, 2019).

38. World Health Organization (WHO). Global Tuberculosis Report 2017. Geneva: World Health Organization (2018). doi: 10.1001/jama.2014.11450

39. Fatima R, Harris RJ, Enarson DA, Hinderaker SG, Qadeer E, Ali K, Bassilli A. Estimating tuberculosis burden and case detection in Pakistan. Int J Tuberc Lung Dis. (2014) 18:55-60. doi: 10.5588/ijtld.13.0198
40. Centers for Disease Control and Prevention. Reported Tuberculosis in the United States, 2002. Atlanta, GA: US Department of Health and Human Services (2003)

41. Cookson ST, Abaza H, Clarke KR, Burton A, Sabrah NA, Rumman KA, et al. Impact of and response to increased tuberculosis prevalence among Syrian refugees compared with Jordanian tuberculosis prevalence: case study of a tuberculosis public health strategy. Confl Health. (2015) 9:18. doi: 10.1186/s13031-015-0044-7

42. Howard N, Guinness L, Rowland M, Durrani N, Hansen KS Cost-effectiveness of adding indoor residual spraying to case management in Afghan refugee settlements in Northwest Pakistan during a prolonged malaria epidemic. PLoS Negl Trop Dis. (2017) 11:e0005935. doi: 10.1371/journal.pntd.0005935

Conflict of Interest Statement: The authors declare that the research was conducted in the absence of any commercial or financial relationships that could be construed as a potential conflict of interest.

Copyright (C) 2019 Malik, Afzal, Farid, Khan, Mirza and Waheed. This is an openaccess article distributed under the terms of the Creative Commons Attribution License (CC BY). The use, distribution or reproduction in other forums is permitted, provided the original author(s) and the copyright owner(s) are credited and that the original publication in this journal is cited, in accordance with accepted academic practice. No use, distribution or reproduction is permitted which does not comply with these terms. 